\title{
Prevalence and predictors of alcohol use among adult males in Ethiopia: multilevel analysis of Ethiopian Demographic and Health Survey 2016
}

\author{
Zemenu Tadesse Tessema ${ }^{1 *}$ (D) and Tadele Amare Zeleke ${ }^{2}$
}

\begin{abstract}
Background: Alcohol is a psychoactive substance that is widely consumed in the world. Alcohol use is one of the world's leading risk factors for disease and disability. It affects individuals' physical, mental, economic, and social issues. To our knowledge, there is limited study on alcohol consumption and associated factors. Therefore, this study aimed to determine the prevalence and predictors of alcohol use in Ethiopia by using the 2016 Ethiopian Demographic and Health Survey.

Methods: This study was based on the most recent Ethiopian Demographic and Health Survey 2016. A total of 12, 594 men at the age of 15 to 59 were included in this study. Considering the hierarchical nature of EDHS data, a multilevel logistic regression model was applied. The ICC, MOR, and the LR test were done to assess the presence of a significant clustering effect. Besides, deviance was used for model comparison since the models were nested models. Variables with a $p$ value $\leq 0.2$ in the bivariable analysis were considered for the multivariable analysis. In the multilevel logistic regression, the adjusted odds ratio (AOR) with 95\% confidence interval (CI) was reported to declare the strength and significance of the association between the dependent variable and independent variables.
\end{abstract}

Results: The prevalence of alcohol drinking in this study was $46.64 \%$ with a $95 \% \mathrm{Cl}$ of 45.00 to $47.00 \%$. Age groups $30-44(\mathrm{AOR}=1.30,95 \% \mathrm{Cl} 1.08,1.56)$ and $45-59(\mathrm{AOR}=1.38,95 \% \mathrm{Cl} 1.10,1.74)$, Orthodox religion follower $(\mathrm{AOR}=$ $0.36,95 \% \mathrm{Cl} 0.24,0.55)$, media exposure ( $\mathrm{AOR}=1.67,95 \% \mathrm{Cl} 1.41,2.20)$, khat chewing ( $\mathrm{AOR}=3.08,95 \% \mathrm{Cl} 2.54$, 3.74), smoking ( $A O R=2.18,95 \% \mathrm{Cl} 1.71,2.79$ ), having no occupation ( $\mathrm{OOR}=0.34,95 \% \mathrm{Cl} 0.22,0.51$ ), and region were the predictors of alcohol use in Ethiopia.

Conclusions: Nearly half of the Ethiopian population reported alcohol use at least once in their lifetime. Old age, Orthodox religion followers, media exposure, khat chewing, smoking, and having no occupation were predictors of alcohol use in Ethiopia. Therefore, health education about the risk of alcohol used is highly recommended. In addition, khat chewing and smoking control mechanisms should be designed and given special attention. Advertising alcohol through media is better to be controlled. Job opportunities should also be created for those who have no occupation to mitigate alcohol use in Ethiopia.

Keywords: Predictor, Ethiopia, Multilevel, Alcohol use

\footnotetext{
* Correspondence: zemenut1979@gmail.com

'Department of Epidemiology and Biostatistics, Institute of Public Health, College of Medicine and Health Science, University of Gondar, Gondar,

Ethiopia

Full list of author information is available at the end of the article
}

(c) The Author(s). 2020, corrected publication 2020. Open Access This article is licensed under a Creative Commons Attribution 4.0 International License, which permits use, sharing, adaptation, distribution and reproduction in any medium or format, as long as you give appropriate credit to the original author(s) and the source, provide a link to the Creative Commons licence, and indicate if changes were made. The images or other third party material in this article are included in the article's Creative Commons licence, unless indicated otherwise in a credit line to the material. If material is not included in the article's Creative Commons licence and your intended use is not permitted by statutory regulation or exceeds the permitted use, you will need to obtain permission directly from the copyright holder. To view a copy of this licence, visit http://creativecommons.org/ licenses/by/4.0/. 


\section{Introduction}

Alcohol is a liquid that contains ethanol and the most predominant beverage worldwide [1]. Alcohol use is one of the world's leading health risks that results in 2.5 million death each year [2]. It is also a causal factor in many diseases and a precursor to injury, violence, and cardiovascular diseases [3]. Worldwide, alcohol use is associated with maternal and child health problems, risky sexual behavior, unintended pregnancy, injury, and poisoning [1]. Alcohol use triggers a host of public health harms, from injury and death accompanied by excessive drinking to increased violence, crime, poverty, and other forms of social destabilization, financial, disease, and death [4-6].

Alcohol is one of the most used and misused substances in different societies [7]. Due to alcohol drinking, 3 million Canadians are at risk of acute illness [8]. Alcohol is widely consumed by more than half of the population in the Americas, Europe, and the Western Pacific [1]. In Europe, alcohol leads to ischemic cardiovascular disease and injury, and death [9]. In England, about 10 million people are drinking at a level of which increases their risk of health problems. In age 15 to 49 , alcohol is the leading cause of ill health, early mortality, and disability and the fifth leading cause for ill health in all age groups [10].

In low- and middle-income countries, alcohol use disproportionately affects premature mortality and disability [11]. In African countries, alcohol consumption has a large impact on the burden of disease and mortality, and alcohol exposure is expected to increase in the next years [12]. In the African continent, alcohol industry involvement and investment are rising following a general strategy to increase demand, availability, and access to alcoholic beverages [13].

Studies had been reported that the lifetime prevalence of alcohol use in New Zealand was 95.0\% [5], in India 49.7\% [14], in Nigeria 57.9\% [15], in Uganda 51.4\% [16], in Nigeria $76.0 \%$ [17], in Kenya $10.8 \%$ [18], and in Sri Lanka $53.7 \%$ [19].

Contributing factors for alcohol use were male sex [15, 20-23], being Christian followers (51.6\%) [22], smoking [20, 23, 24], age 20-29 [20], increasing age, poor social support [25], being age 30 and older, low level of education [26, 27], and being in lower socioeconomic groups [28].

Alcohol advertising and marketing are misleading the public in order to entice them to consume alcohol [21, 29]. As a result, alcohol consumption is common and widely acceptable across all categories of people [30].

In Gondar Ethiopia, the prevalence of ever alcohol use was 48.23\% [22]; in Ethiopia, systematic review and meta-analysis, pooled current and lifetime alcohol use were $23.86 \%$ and $44.16 \%$ respectively [31]. In another community study conducted in Ambo, Ethiopia, the prevalence of alcohol use disorder was 27\% [32]. Alcohol consumption in Ethiopia is a risk factor for infectious diseases (tuberculosis, lower respiratory infections, viral hepatitis, sexually transmitted diseases including HIV), non-communicable diseases (heart diseases, noninfectious liver diseases, cancer), and mental disorders (alcohol use disorders including depression) [2]. As far as we know, in Ethiopia, studies showed that alcohol is the risk for different diseases and injuries rather than showed cause and effect relationship. Even though the risk of alcohol use is known in Ethiopia, less emphasis is given to the prevention strategies and the management of hazardous alcohol drinkers and addicted individuals [7]. Today, in Ethiopia, alcohol advertisement is prohibited with proclamation No. 759/2012. Advertised liquor with more than $12 \%$ alcoholic content may not be disseminated through mass media. Any liquor outdoor advertisement may not be placed within 100-m radius of children care center, school, medical or historical institution, cinema, theatre, and stadiums [33]. However, the fact is that this is not implemented. To our knowledge, there is a limited study on alcohol consumption and associated risk factors. Therefore, this study aimed to determine the prevalence and predictors of alcohol use in Ethiopia using the 2016 Ethiopian Demographic and Health Survey. The finding is crucial for policymakers and health professionals for effective intervention.

\section{Methods \\ Study area}

Ethiopia is found in East Africa of WHO region. It is located in the horn of Africa. Ethiopia had nine regions and two city administrations as shown in Fig. 1.

\section{Data source}

We used data from the most recent Ethiopian Demographic and Health Survey 2016 conducted in January 18,2016 , to June 27, 2016. It is conducted every 5 -year interval. The survey had different datasets (individual records, kids record, household record, men records, birth cohort records etc.). For this study, men's record (MR) dataset was used. The data was freely accessible, and permission was obtained after projects are designed and submitted. The detail is found elsewhere [34].

\section{Sampling procedure}

A two-stage stratified sampling procedure was adopted in selecting study participants. The detail of sampling procedure is found elsewhere [35]. All men aged 15-59 who had been interviewed about ever alcohol drinking were included in the study. However, respondents with missing data for the outcome variable were excluded. A total of 14,795 eligible male respondents were selected, 


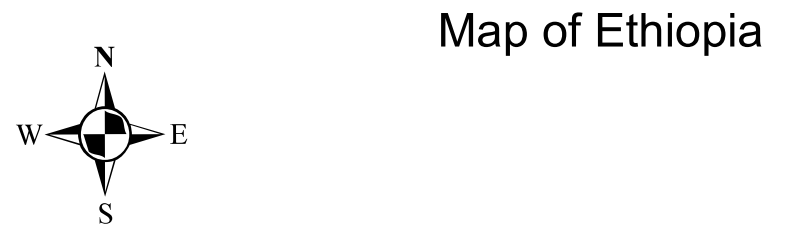

Legend

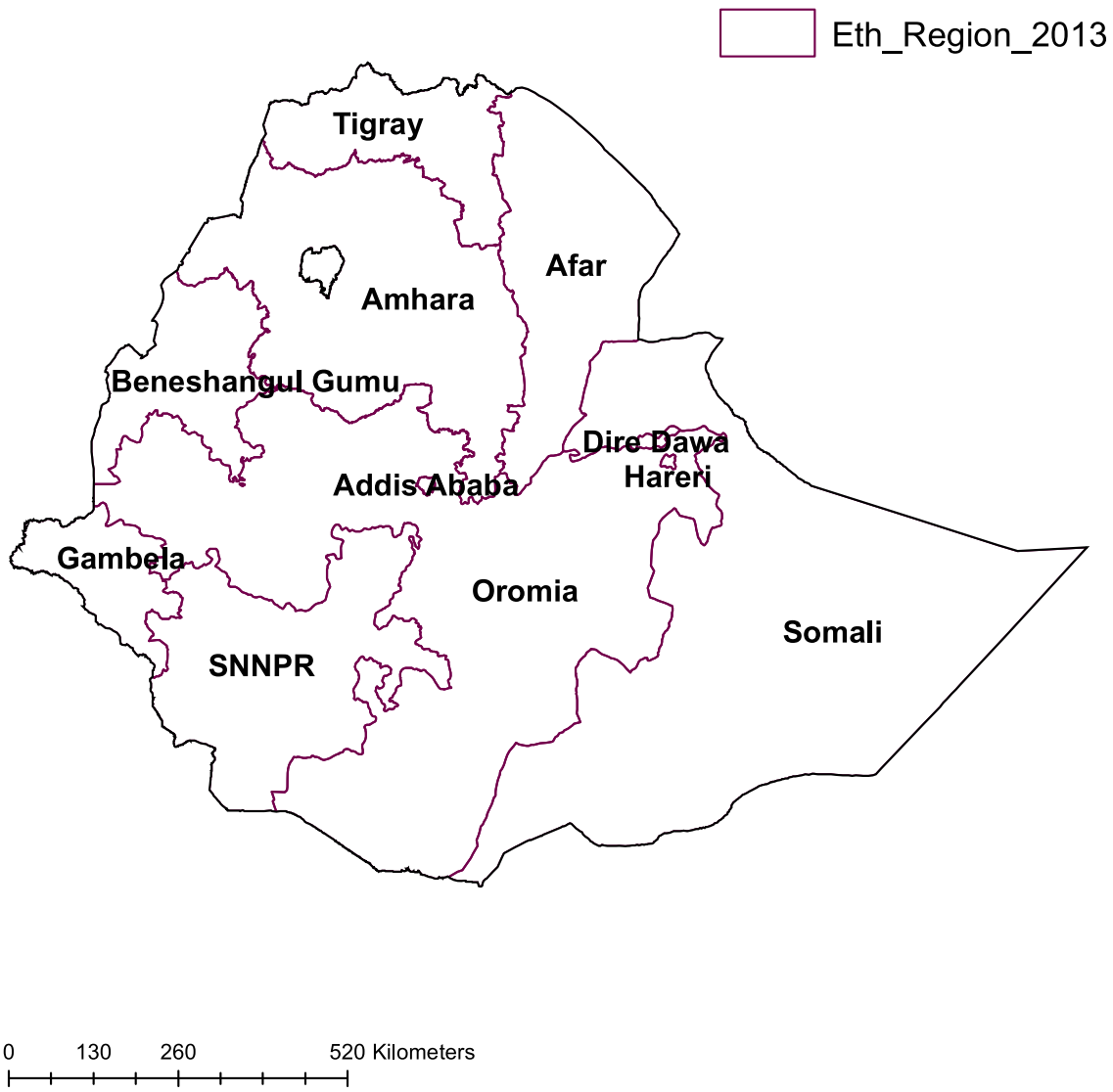

Fig. 1 Map of study area

and 12,594 were successfully interviewed, and the response rate was $85.12 \%$.

\section{Variables of the study}

Outcome variable Respondents' ever alcohol drinking status, the outcome variable in this study, was defined as a person who ever drinks alcohol in his lifetime.

Independent variables The independent variables were grossly classified into the individual-level and communitylevel variables: Individual-level variable includes ever chewed khat, age, religion, marital status, educational status, sex of household head, working status, occupation, source of information (reading newspaper, reading magazines, and watching television), and wealth index (poor, middle and rich). The community-level variables include residence and region.

\section{Operational definition}

Ever alcohol drinking was defined as a respondent who drinks alcohol during his lifetime.

Ever chat chewer was defined as a respondent who chewed chat during his lifetime.

\section{Data analysis procedure}

To identify the predictors of alcohol use, the STATA 14 software was used. Sampling weight was done before any statistical analysis to adjust for the non-proportional allocation of the sample to different countries and the possible differences in response rates. Since the DHS data has 
Table 1 Socio-demographic characteristics of adult men 15-59 years in Ethiopia, EDHS 2016

\begin{tabular}{|c|c|c|c|}
\hline \multirow[t]{2}{*}{ Variables } & \multicolumn{2}{|c|}{ Ever use alcohol } & \multirow[t]{2}{*}{ Total (\%) } \\
\hline & Yes & No & \\
\hline \multicolumn{4}{|l|}{ Ever chewed khat } \\
\hline Yes & 855 & 2562 & $3418(72.86)$ \\
\hline No & 4157 & 5018 & 9176 (72.86) \\
\hline \multicolumn{4}{|l|}{ Age group } \\
\hline $15-29$ & 3640 & 2786 & $6426(51.03)$ \\
\hline $30-44$ & 2056 & 2116 & 4173 (33.13) \\
\hline $45-59$ & 1030 & 9364 & 1995 (15.84) \\
\hline \multicolumn{4}{|c|}{ Sex of the household head } \\
\hline Male & 5141 & 5893 & $11,034(87.61)$ \\
\hline Female & 732 & 827 & 1560 (12.39) \\
\hline \multicolumn{4}{|l|}{ Marital status } \\
\hline Married & 3726 & 3977 & 7704 (61.17) \\
\hline Single & 2147 & 2742 & 4890 (38.83) \\
\hline \multicolumn{4}{|l|}{ Residence } \\
\hline Urban & 1415 & 1080 & 2495 (19.82) \\
\hline Rural & 4458 & 5640 & $10,098(80.18)$ \\
\hline \multicolumn{4}{|l|}{ Religion } \\
\hline Orthodox & 4939 & 732 & $5676(45.07)$ \\
\hline Muslim & 345 & 3570 & 3916 (31.09) \\
\hline Protestant & 477 & 2267 & $2745(21.80)$ \\
\hline Others* & 111 & 144 & $256(2.03)$ \\
\hline \multicolumn{4}{|l|}{ Education } \\
\hline No education & 1922 & 1846 & 3773 (29.96) \\
\hline Primary & 2452 & 3424 & $5876(46.66)$ \\
\hline Secondary & 850 & 994 & $1845(14.66)$ \\
\hline Higher & 643 & 455 & 1099 (8.73) \\
\hline \multicolumn{4}{|l|}{ Region } \\
\hline Tigray & 723 & 11 & $794(6.31)$ \\
\hline Afar & 8 & 73 & $82(0.65)$ \\
\hline Amhara & 2679 & 527 & 3206 (25.46) \\
\hline Oromia & 1239 & 3474 & 4713 (37.43) \\
\hline Somali & 2 & 323 & $326(2.59)$ \\
\hline Benishangul & 60 & 63 & $123(0.98)$ \\
\hline SNNPR & 674 & 1911 & 2586 (20.53) \\
\hline Gambela & 19 & 17 & $36(0.29)$ \\
\hline Harari & 5 & 26 & $31(0.25)$ \\
\hline Addis Ababa & 441 & 179 & $620(4.93)$ \\
\hline Dire-Dawa & 19 & 52 & $71(0.57)$ \\
\hline \multicolumn{4}{|l|}{ Media exposure } \\
\hline Yes & 4365 & 3788 & 8154 (64.74) \\
\hline No & 1508 & 2932 & 4440 (35.26) \\
\hline \multicolumn{4}{|l|}{ Wealth index } \\
\hline Poor & 1754 & 2518 & 4272 (33.92) \\
\hline
\end{tabular}


Table 1 Socio-demographic characteristics of adult men 15-59 years in Ethiopia, EDHS 2016 (Continued)

\begin{tabular}{|c|c|c|c|}
\hline \multirow[t]{2}{*}{ Variables } & \multicolumn{2}{|c|}{ Ever use alcohol } & \multirow[t]{2}{*}{ Total (\%) } \\
\hline & Yes & No & \\
\hline Middle & 1087 & 1339 & $2427(19.27)$ \\
\hline Rich & 3031 & 2863 & $5895(46.81)$ \\
\hline \multicolumn{4}{|l|}{ Working status } \\
\hline Yes & 5266 & 5905 & $11,172(88.71)$ \\
\hline No & 607 & 815 & $1422(11.29)$ \\
\hline \multicolumn{4}{|l|}{ Occupation } \\
\hline Had occupation & 5545 & 6105 & $16,650(92.50)$ \\
\hline Had no occupation & 328 & 615 & $944(7.50)$ \\
\hline \multicolumn{4}{|l|}{ Literacy } \\
\hline Can read & 4101 & 4476 & $8578(68.11)$ \\
\hline Cannot read & 1772 & 2244 & 4016 (31.89) \\
\hline
\end{tabular}

hierarchical nature, measures of community variation/random-effects (intraclass correlation coefficient, median odds ratio [36], and proportional change in variance [37]) were estimated. The values of these measures were significant, indicating the use of a multilevel logistic regression model than ordinary logistic regression.

Model comparison was done using deviance between the null-model (a model with no independent variable), model I (a model with only individual-level factors), model II (a model with community-level factors), and model III (a model that contain both individual and communitylevel independent variables). A model with the lowest deviance (model III) was the best-fitted model.

Both bivariable and multivariable multilevel logistic regression were performed to identify the determinant factors of zinc utilization in Ethiopia. All variables with a $p$ value $<0.25$ at bivariable multilevel logistic model analysis were entered into the multivariable multilevel logistic regression model. $p$ value $\leq 0.05$ was used to declare statistically significant variables in the final model.

\section{Result}

\section{Sociodemographic characteristics}

Total weighted samples of 12,594 participants were included in the analysis. The median age of the respondent was 29 with an interquartile range (IQR) of 21-39. Almost half of the participants, 6426 (51.03\%) were between the age of 15 and 29 years. The majority, 10,098 (80.18\%), of the men were rural. The majority, 8154 (64.74\%), of them had media exposure. 5876 (46.66\%) men were in the primary education class. Around two-third of 7705 (61.17\%) participants were married (Table 1).

\section{Random effect analysis}

This study fits a model that considers the nature of the dataset. As known, the EDHS dataset had hierarchical nature. Therefore, fitting models that consider nature of the data is important. We fitted a generalized linear mixed effects model that had two component random effect and mixed effect. The fixed effect measures using odds ratio with the selected independent variables to qualify the effect size of low intake of food rich in vitamin $A$ and independent variables. The random effect measures the variability of low intake of food rich in vitamin A. The variability measure for the random effect is community variance $(1.34, p$ value $<0.001)$; intraclass correlation (ICC) (77.82\%) indicates that there is intake of food rich in vitamin $\mathrm{A}$ at cluster level, median odds ratio (MOR) (3.83) means that if we randomly select children from different clusters, children at cluster of intake of food rich in vitamin A had 3.83 times higher odds of intake of food rich in vitamin A compare to its counterpart, and proportional change in variance (PCV) in model III was $88.38 \%$ the model best explains the variability of low intake of food rich in vitamin A. Model comparison was done using deviance. The lowest deviance (model III) was the best-fit model for this study (Table 2).

\section{Fixed effects analysis result}

The age group has a significant effect on alcohol drinking. The odds of alcohol drinking when compared with people 15-20 years of age or older $(20-34,35-49)$ increase by $30 \%$ and $38 \%(\mathrm{AOR}=1.30,95 \%$ CI $1.08,1.56$ and $\mathrm{AOR}=1.38,95 \% \mathrm{CI} 1.10,1.74)$. Being Muslim, Protestant, and other religion follower decreases the odds of alcohol drinking 99.4\%, 95\%, and 64\% (AOR = 0.006, 95\% CI 0.005, 0.008; AOR $=0.05,95 \%$ CI 0.039 , 0.062 ; and $\mathrm{AOR}=0.36,95 \% \mathrm{CI} 0.24,0.55)$ as compared to Orthodox religion followers respectively. Media exposure had a relationship with alcohol drinking. The odds of alcohol drinking among media-exposed men increase by $67 \%$ as compared to non-exposed men (AOR 
Table 2 Multilevel logistic regression analysis of both individual and community-level factors associated with alcohol use in Ethiopia, EDHS 2016

\begin{tabular}{|c|c|c|c|c|}
\hline \multirow{3}{*}{$\begin{array}{l}\text { Individual and } \\
\text { community-level } \\
\text { variables }\end{array}$} & \multicolumn{4}{|l|}{ Models } \\
\hline & Null model & Model I & Model II & Model III \\
\hline & AOR $(95 \% \mathrm{Cl})$ & AOR $(95 \% \mathrm{Cl})$ & AOR $(95 \% \mathrm{Cl})$ & AOR $(95 \% \mathrm{Cl})$ \\
\hline \multicolumn{5}{|l|}{ Men age } \\
\hline $15-29$ years & & 1 & & 1 \\
\hline 30-44 years & & $1.28(1.07,1.54)$ & & $1.30(1.08,1.56)^{*}$ \\
\hline $45-59$ years & & $1.38(1.09,1.74)$ & & $1.38(1.10,1.74)^{*}$ \\
\hline \multicolumn{5}{|l|}{ Household head } \\
\hline Male & & 1 & & 1 \\
\hline Female & & $1.05(0.87,1.27)$ & & $1.09(0.90,1.32)$ \\
\hline \multicolumn{5}{|l|}{ Marital status } \\
\hline Had a partner & & 1 & & 1 \\
\hline Not having a partner & & $0.78(0.65,0.94)$ & & $0.78(0.64,1.02)$ \\
\hline \multicolumn{5}{|l|}{ Religion } \\
\hline Orthodox & & 1 & & 1 \\
\hline Muslim & & $0.006(0.005,0.08)$ & & $0.01(0.008,0.044)$ \\
\hline Protestant & & $0.05(0.039,0.062)$ & & $0.06(0.054,0.083)$ \\
\hline Others & & $0.36(0.24,0.55)$ & & $0.42(0.28,0.63)$ \\
\hline \multicolumn{5}{|l|}{ Men education } \\
\hline Unable to read and write & & 1 & & 1 \\
\hline Primary education & & $0.83(0.65,1.06)$ & & $0.87(0.68,1.11)$ \\
\hline Secondary education & & $0.74(0.55,0.99)$ & & $0.80(0.60,1.08)$ \\
\hline Higher education & & $1.30(0.95,1.78)$ & & $1.40(0.99,1.92)$ \\
\hline \multicolumn{5}{|l|}{ Men working status } \\
\hline Not working & & 1 & & 1 \\
\hline Working & & $0.78(0.54,1.12)$ & & $0.83(0.57,1.02)$ \\
\hline \multicolumn{5}{|l|}{ Media exposure } \\
\hline No exposed & & 1 & & 1 \\
\hline Exposed & & $1.67(1.40,2.00)$ & & $1.69(1.41,2.20)^{*}$ \\
\hline \multicolumn{5}{|l|}{ Wealth index } \\
\hline Poor & & 1 & & 1 \\
\hline Middle & & $0.91(0.73,1.13)$ & & $0.85(0.68,1.06)$ \\
\hline Richer & & $0.84(0.69,1.03)$ & & $0.83(0.68,1.03)$ \\
\hline \multicolumn{5}{|l|}{ Smoking status } \\
\hline Non-smoker & & 1 & & 1 \\
\hline Smoker & & $1.89(1.48,2.41)$ & & $2.18(1.71,2.79)^{*}$ \\
\hline \multicolumn{5}{|l|}{ Khat chewing } \\
\hline No & & 1 & & 1 \\
\hline Yes & & $2.77(2.28,3.37)$ & & $3.08(2.54,3.74)^{*}$ \\
\hline \multicolumn{5}{|l|}{ Occupation } \\
\hline Had occupation & & 1 & & 1 \\
\hline Had no occupation & & $0.30(0.20,0.46)$ & & $0.34(0.22,0.51)^{*}$ \\
\hline \multicolumn{5}{|l|}{ Literacy } \\
\hline Can read & & 1 & & 1 \\
\hline
\end{tabular}


Table 2 Multilevel logistic regression analysis of both individual and community-level factors associated with alcohol use in Ethiopia, EDHS 2016 (Continued)

\begin{tabular}{|c|c|c|c|c|}
\hline \multirow{3}{*}{$\begin{array}{l}\text { Individual and } \\
\text { community-level } \\
\text { variables }\end{array}$} & \multicolumn{4}{|l|}{ Models } \\
\hline & Null model & Model I & Model II & Model III \\
\hline & AOR $(95 \% \mathrm{Cl})$ & AOR $(95 \% \mathrm{Cl})$ & AOR $(95 \% \mathrm{Cl})$ & AOR $(95 \% \mathrm{Cl})$ \\
\hline Cannot read & & $0.95(0.76,1.19)$ & & $1.01(0.80,1.26)$ \\
\hline \multicolumn{5}{|l|}{ Residence } \\
\hline Urban & & & 1 & 1 \\
\hline Rural & & & $0.27(0.17,0.41)$ & $0.80(0.56,1.15)$ \\
\hline \multicolumn{5}{|l|}{ Region } \\
\hline Tigray & & & 1 & 1 \\
\hline Afar & & & $.0007(.0003,0.0007)$ & $0.02(0.009,0.042)^{*}$ \\
\hline Amhara & & & $0.62(0.31,1.25)$ & $1.05(0.61,1.81)$ \\
\hline Oromia & & & $0.008(0.004,0.017)$ & $0.06(0.039,0.11)^{*}$ \\
\hline Somali & & & $0.0001(0.0003,0.00)$ & $0.004(0.001,0.011)^{*}$ \\
\hline Benishangul & & & $0.04(0.021,0.093)$ & $0.33(0.18,0.58)^{*}$ \\
\hline SNNPR & & & $0.1(0.005,0.02)$ & $0.07(0.04,0.12)^{*}$ \\
\hline Gambela & & & $0.03(0.016,0.073)$ & $0.15(0.08,0.27)^{*}$ \\
\hline Harari & & & $0.02(0.001,0.005)$ & $0.01(0.008,0.032)^{*}$ \\
\hline Addis Ababa & & & $0.048(0.02,0.106)$ & $0.21(0.11,0.39)^{*}$ \\
\hline Dire Dawa & & & $0.003(0.001,0.007)$ & $0.03(0.016,0.059)^{*}$ \\
\hline \multicolumn{5}{|l|}{ Random effects } \\
\hline ICC\% & 77.82 & 47.23 & 48.84 & 29.04 \\
\hline PCV\% & 1 & 74.52 & 72.79 & 88.38 \\
\hline MOR & 51.41 & 7.33 & 7.83 & 3.83 \\
\hline \multicolumn{5}{|l|}{ Model fitness } \\
\hline Log-likelihood ratio & -5224 & -3920 & -4907 & -3690 \\
\hline Deviance & 10448 & 7840 & 9817 & 7380 \\
\hline
\end{tabular}

$\mathrm{Cl}$ confidence interval, $A O R$ adjusted odds ratio, Others traditional religion followers

*Significant at $p$ value $=0.05$

$=1.67,95 \%$ CI 1.41, 2.20). Smoking had a significant effect on alcohol drinking. The odds of alcohol drinking among smokers were 2.18 times higher risk as compared to non-smokers $(\mathrm{AOR}=2.18 ; 95 \% \mathrm{CI} 1.41,2.20)$. There is a strong relationship between khat chewing and alcohol drinking. The odds of alcohol drinking among khat chewers were 3.08 times higher as compared to nonkhat chewers $(\mathrm{AOR}=3.08,95 \% \mathrm{CI} 2.54,3.74)$. There is a relationship between the occupation of men and alcohol drinking. The odds of alcohol drinking among men who had occupation decrease by $66 \%$ as compared to men who had no occupation (AOR $=0.34,95 \%$ CI 0.22 , 0.51). The odds of alcohol drinking among men who live other than in Tigray decreases (Table 2).

\section{Discussion}

This study showed the prevalence and associated factors of alcohol use in Ethiopia using the Ethiopian Demographic and Health Survey of 2016. The prevalence of lifetime alcohol use was $46.64 \%$ (95\% CI $45-47 \%$ ). The current finding was significantly lower than other findings in New Zealand [5], in India [14], in Nigeria [15], in Uganda [16], and in Nigeria [17]. The discrepancy might be due to that in New Zealand the age was 16-64 years, and the survey was a cohort study. In India, the study was conducted on only rural area dwellers, who are a highly vulnerable population for alcohol use, which is supported by other findings [24]. In Nigeria, researches were conducted in semirural dwellers and militaries who were more prevalent in the alcohol use population. In Sri Lanka, the study participants were mentally ill individuals.

When compared with people 15-20 years of age or older (20-34, 35-49), individuals have a higher risk alcohol use. This finding is consistent with other studies that have found an association of alcohol use with increasing age [24] and of being aged 30 and over [25, 26]. Possible reasons include older people are independent of family control, and they have also their own income generation. 
Muslim, Protestant, and other religion followers decrease the odds of alcohol drinking 99.4\%, 95\%, and 64\% as compared to Orthodox religion followers. The finding is consistent with other findings $(51.6 \%)[15,20]$. The reason might be Orthodox followers are culturally accepted in Ethiopia to drink alcohol.

In this study, the odds of alcohol use was about 1.69 $[\mathrm{AOR}=1.69 ; 95 \% \mathrm{CI}(1.14,2.20)]$ times higher than those who were following media as compared to individuals who were not following media. There is evidence that alcohol consumption increase in Ethiopia from time to time [22]. Currently in Ethiopia, alcohol advertising though media is stopped by the Ethiopian government [31].

The study participants who smoked tobacco and chewed khat were highly significant with alcohol use when compared with their counterparts. This finding is supported by other findings $[20,23,24]$. The reason could be the action of alcohol is sedation [38]; to break the sedation, alcohol user also uses stimulants like khat and cigarette to get the feeling of being energized and hyperalert [39].

The odds of alcohol drinking among men who had occupations decreased by $66 \%$ as compared to men who had no occupation. This finding is supported by studies elsewhere [40]. Unemployment is an important factor for alcohol use, and problematic alcohol use crimp the likelihood of unemployment and decreases the chance of finding and holding down a job [41-43]. In Ethiopia, the government has no control over the production of locally brewed alcoholic drinks. Therefore, alcoholic beverage is found everywhere and everybody can access at low cost [44]. Unemployed men have more time available during the day in which to drink alcohol.

\section{Conclusion}

Nearly half of the Ethiopian population reported alcohol use at least once in their lifetime. Old age, being Orthodox religion followers, media exposure, khat chewing, smoking, and having no occupation were predictors of alcohol use in Ethiopia. Therefore, health education about the risk of alcohol used is highly recommended. In addition, khat chewing and smoking control mechanisms should be designed and given spatial attention. Job opportunities should be also created for the majority of society to alleviate alcohol use in Ethiopia.

\section{Limitation of the study}

Since the study is cross-sectional, it is not possible to establish a causal relationship between the independent and dependent variables. The study did not look at the pattern (frequency, dose) of alcohol use, harmful drinking, clinical aspects and consequences of dependence, and the consequence. The outcome measure for this study was by asking questions not by blood chemistry confirmation, and this may affect this study result.

\section{Abbreviations}

AOR: Adjusted odds ratio; Cl: Confidence; LLR: Likelihood ratio; RR: Relative risk; SNNPR: South Nation Nationalities of People Regions; EDHS: Ethiopian Demographic and Health survey

\section{Acknowledgements}

We would like to thank the Ethiopian Central Statistics Agency for providing us with all the relevant secondary data used in this study. Finally, we would like to thank all who directly or indirectly supported us.

\section{Authors' contributions}

ZTT and TAZ conceived the study, were involved in the study design and data analysis, drafted the manuscript, and critically reviewed the manuscript. Both authors read and approved the final manuscript.

\section{Funding}

We did not receive external funds for this research.

\section{Availability of data and materials}

The datasets used during the current study are available from the corresponding author.

\section{Ethics approval and consent to participate}

The data is secondary and we received a permission letter from measure DHS at www.measuredhs.com. According to the EDHS 2016 report, written informed consent from study participants age less than 16 was obtained from the guardian. The details of the report can be accessed at [34].

Consent for publication

Not applicable.

\section{Competing interests}

The authors declared that they have no competing interests.

\section{Author details}

${ }^{1}$ Department of Epidemiology and Biostatistics, Institute of Public Health, College of Medicine and Health Science, University of Gondar, Gondar, Ethiopia. ${ }^{2}$ Department of Psychiatry School of Medicine, College of Medicine and Health Science, University of Gondar, Gondar, Ethiopia.

Received: 8 June 2020 Accepted: 19 November 2020

Published online: 07 December 2020

\section{References}

1. World Health Organization. Global status report on alcohol and health 2018. World Health Organization; 2019.

2. Beyene N. Alcohol control policy in Ethiopia and implications for public health. J Public Health Policy. 2019;40(4):423-35.

3. Alwan A. Global status report on alcohol and health. World Heal Organ WHO Libr Cat Data, Geneva, Switz. 2011;2-85.

4. Wood D. A review of research on alcohol and drug use, criminal behavior, and the criminal justice system response in American Indian and Alaska Native communities. Vancouver: Washington State University Vancouver, Program in Public Affairs; 2009.

5. Mason K, Bhattacharya A, Stefanogiannis N. Alcohol use in New Zealand: key results of the 2007/08 New Zealand alcohol and drug use survey. Wellington: Ministry of Health; 2009.

6. Friday J. Present: Chief Justice Roberts, Justice Thomas, Justice Ginsburg, Justice Breyer, Justice Alito, Justice Sotomayor, Justice Kagan, Justice Gorsuch, and Justice Kavanaugh.

7. Essau CA, Hutchinson D. Alcohol use, abuse and dependence. In: Adolescent addiction. Academic Press; 2008. p. 61-115.

8. Rabie M, Shaker NM, Gaber E, El-Habiby M, Ismail D, El-Gaafary M, et al. Prevalence updates of substance use among Egyptian adolescents. Middle East Curr Psychiatry. 2020;27(1):4.

9. Rehm J, Zatonksi W, Taylor B, Anderson P. Epidemiology and alcohol policy in Europe. Addiction. 2011;106:11-9.

10. Burton R, Henn C, Lavoie D, O'Connor R, Perkins C, Sweeney K, et al. The public health burden of alcohol and the effectiveness and cost-effectiveness of alcohol control policies: an evidence review. Public Heal Burd alcohol Eff cost-effectiveness alcohol Control policies an Evid Rev. 2016; 
11. Medina-Mora ME, Monteiro M, Room R, Rehm J, Jernigan D, SánchezMoreno D, et al. Alcohol use and alcohol use disorders. Dis Control Priorities. 2015:4:127-43.

12. Ferreira-Borges $C$, Rehm J, Dias S, Babor T, Parry CDH. The impact of alcohol consumption on African people in 2012: an analysis of burden of disease. Trop Med Int Heal. 2016;21(1):52-60.

13. Babor TF, Robaina K, Jernigan D. The influence of industry actions on the availability of alcoholic beverages in the African region. Addiction. 2015; 110(4):561-71.

14. Bute J, Kori S, Arora VK, Sahasrabuddhe A. Prevalence and pattern of alcohol consumption among males attending primary health care setting using AUDIT in rural Indore, Madhya Pradesh, India. Int J Community Med Public Heal. 2018:5(10):4461.

15. Lasebikan VO, Ola BA. Prevalence and correlates of alcohol use among a sample of Nigerian semirural community dwellers in Nigeria. J Addict. 2016;2016.

16. Kuteesa MO, Weiss HA, Cook S, Seeley J, Ssentongo JN, Kizindo R, et al. Epidemiology of alcohol misuse and illicit drug use among young people aged 15-24 years in fishing communities in Uganda. Int J Environ Res Public Health. 2020;17(7):2401.

17. Ijomanta IN, Lasebikan VO. Lifetime and 12 months prevalence of alcohol use and alcohol use disorders among soldiers residing in a military community in Ibadan. Subst Use Misuse. 2016;51(6):722-32.

18. Jenkins R, Othieno C, Ongeri L, Kiima D, Sifuna P, Kingora J, et al. Alcohol consumption and hazardous drinking in western Kenya-a household survey in a health and demographic surveillance site. BMC Psychiatry. 2015;15(1):1-10.

19. Abeysena C, Hapugoda C. Prevalence of alcohol, tobacco and illicit narcotic substances usage and associated factors among patients attending mental health clinics conducted by a group of hospitals in Sri Lanka; 2018.

20. Reisdorfer E, Büchele F, Pires ROM, Boing AF. Prevalence and associated factors with alcohol use disorders among adults: a population-based study in southern Brazil. Rev Bras Epidemiol. 2012;15(3):582-94.

21. Negussie $H$, Berhane $Y$. Assessment of alcohol advertising practices in Ethiopia. Ethiop J Heal Dev. 2012;26(3):216-25

22. Yismaw $\mathrm{S}$, Kebede $\mathrm{H}$. Prevalence and associated factors of alcohol consumption among college students in Gondar Town, Northwest Ethiopia. Sci J Public Heal. 2015;3(4):453-9.

23. Murphy A, Roberts B, Stickley A, McKee M. Social factors associated with alcohol consumption in the former Soviet Union: a systematic review. Alcohol Alcohol. 2012;47(6):711-8.

24. Getachew T, Defar A, Teklie H, Gonfa G, Bekele A, Bekele A, et al. Magnitude and predictors of excessive alcohol use in Ethiopia: findings from the 2015 national non-communicable diseases STEPS survey. Ethiop J Heal Dev. 2017; 31(1):312-9.

25. Teferra S, Medhin G, Selamu M, Bhana A, Hanlon C, Fekadu A. Hazardous alcohol use and associated factors in a rural Ethiopian district: a crosssectional community survey. BMC Public Health. 2016;16(1):218.

26. Poelen EAP, Scholte RHJ, Engels RCME, Boomsma DI, Willemsen G. Prevalence and trends of alcohol use and misuse among adolescents and young adults in the Netherlands from 1993 to 2000. Drug Alcohol Depend. 2005;79(3):413-21.

27. Klein $\mathrm{H}$, Sterk CE, Elifson KW. The prevalence of and factors associated with alcohol-related problems in a community sample of African American women. J Addict. 2016;2016.

28. Allen LN, Townsend N, Williams J, Mikkelsen B, Roberts N, Wickramasinghe K. Socioeconomic status and alcohol use in low-and lower-middle income countries: a systematic review. Alcohol. 2018;70:23-31.

29. Letsela L, Weiner R, Gafos M, Fritz K. Alcohol availability, marketing, and sexual health risk amongst urban and rural youth in South Africa. AIDS Behav. 2019;23(1):175-89.

30. Ssebunnya J, Kituyi C, Nabanoba J, Nakku J, Bhana A, Kigozi F. Social acceptance of alcohol use in Uganda. BMC Psychiatry. 2020;20(1):1-7.

31. Ayano G, Yohannis K, Abraha M, Duko B. The epidemiology of alcohol consumption in Ethiopia: a systematic review and meta-analysis. Subst Abus Treat Prev Policy. 2019;14(1):1-16.

32. Birhanu A, Mekuria M. Prevalence of Alcohol Use Disorders and Associated Factors among Ambo Town Community, Central Ethiopia: A Community Based Cross-Sectional Study. J Addict Res Ther. 2019;10(4):1000389.

33. Gazeta FN. Negarit News "3つ67.

34. 2016 CSA (CSA) [Ethiopia] and ICF. Ethiopia Demographic and Health Survey 2016: key indicators report. Addis Ababa and Rockville: CSA ICF; 2016.

35. Demographic T, Program HS. Guide to DHS Statistics.
36. Goldstein H, Browne W, Rasbash J. Partitioning variation in multilevel models. Understanding Statistics: Statistical Issues in Psychology, Education, and the Social Sciences. 2002;1(4):223-31.

37. Merlo J, Chaix B, Lynch J, Råstam L, Min Y. A brief conceptual tutorial on multilevel analysis in social epidemiology: investigating contextual phenomena in different groups of people. J Epidemiol Community Heal. 2005;59(9):729-36.

38. Lieber CS. NIAAA and alcohol research: a researcher's view. Alcohol Heal Res World. 1989:13(4):301-5.

39. Hassan G, Kirmayer $\sqcup$, Mekki-Berrada A, Quosh C, El Chammay R, Deville-Stoetzel $J-B$, et al. Culture, context and the mental health and psychosocial wellbeing of Syrians: a review for mental health and psychosocial support staff working with Syrians affected by armed conflict. Geneva: UNHCR; 2015. p. 14-5.

40. Marchand A. Alcohol use and misuse: what are the contributions of occupation and work organization conditions? BMC Public Health. 2008;8:1-12.

41. Montgomery SM, Cook DG, Bartley MJ, Wadsworth ME. Unemployment, cigarette smoking, alcohol consumption and body weight in young British men. Eur J Public Health. 1998;8(1):21-7.

42. De Goeij MCM, Willem J, Ferdy B, Anton O. Harmful drinking after job loss: a stronger association during the post-2008 economic crisis ? Int J Public Health. 2017;62(5):563-72.

43. Henkel D.Unemployment and substance use: a review of the literature (1990-2010). Current drug abuse reviews. 2011;4(1):4-27.

44. Profiles C, Region A. African Region; 2004

\section{Publisher's Note}

Springer Nature remains neutral with regard to jurisdictional claims in published maps and institutional affiliations.
Ready to submit your research? Choose BMC and benefit from:

- fast, convenient online submission

- thorough peer review by experienced researchers in your field

- rapid publication on acceptance

- support for research data, including large and complex data types

- gold Open Access which fosters wider collaboration and increased citations

- maximum visibility for your research: over $100 \mathrm{M}$ website views per year

At $\mathrm{BMC}$, research is always in progress.

Learn more biomedcentral.com/submissions 